\title{
Diamela Eltit: categorías metafóricas, interacción comunicativa y memoria en El Padre Mío
}

\section{DIAMELA ELTIT: METAPHORICAL CATEGORIES, COMMUNICATIVE INTERACTION AND MEMORY IN EL PADRE MÍO}

\author{
Edith Pérez Orozco \\ Universidad Nacional Federico Villarreal \\ thelian68_8@hotmail.com
}

\section{RESUMEN}

Diamela Eltit es una renombrada escritora chilena. Su proyecto estético y político se orienta hacia la recuperación de las voces marginadas y la construcción del lenguaje fragmentado y encriptado ante la imposibilidad de la comunicación lingüística, además de la puesta en escena de subjetividades dialógicas y polifónicas que hacen de sus textos narrativos piezas representativas de la literatura latinoamericana. En este artículo estudiamos el texto El Padre Mío (1989) y analizamos las categorías culturales y metafóricas como propuesta estética; luego, examinamos el texto propiamente recurriendo a las categorías de interacciones comunicativas de Thompson (1998) y determinamos la memoria narrativa o "memorable" siguiendo la propuesta de Jelin (2002).

PALABRAS CLAVE: literatura chilena, categorías metafóricas, interacciones comunicativas, memoria

\section{ABSTRACT}

Diamela Eltit is a renowned Chilean writer. Her aesthetic and political project are oriented towards the recovery of marginalized voices, the construction of fragmented and encrypted language in the face of the impossibility of linguistic communication and to the staging of dialogic and polyphonic subjectivities that make his narrative texts representative of Latin American literature. In this article, we study the text El Padre Mío (1989) and analyze the cultural and metaphorical categories as an aesthetic proposal; then we examine the text itself by resorting to the categories of communicative interactions of John B. Thompson (1998), and we determine the narrative or "memorable" memory following the proposal of Jelin (2002).

KEYWORDS: Chilean literature, metaphorical categories, communicative interactions, memory 


\section{INTRODUCCIÓN}

Diamela Eltit, escritora chilena, busca establecer la representación del discurso literario de una manera peculiar y significativa dentro de su producción textual. Su proyecto estético y político se orienta hacia la recuperación de la democracia y la búsqueda de formas simbólicas de socialización (Moraña, 2004). Desde la literatura, sus producciones textuales reflexionan sobre las categorías culturales y metafóricas adecuadas para comprender la situación de la sociedad chilena. Su narrativa transgrede el sistema literario convencional haciendo que su propuesta arremeta contra la tradición de los géneros literarios, pues incluye las acciones performativas de la actuación teatral; apela a los testimonios de las identidades desplazadas y residuales de la ciudad (el loco, el esquizofrénico); vincula la intertextualidad literaria con las disciplinas humanísticas (antropología, arqueología e historia) y los medios audiovisuales (fotografía y grabaciones audiovisuales). Según Reyes (2005), Eltit utiliza las formas discursivas del testimonio y de la ficción con el fin de otorgar al narrador-personaje o protagonista la articulación de sus testimonios en primera persona. Todas estas características son usuales en sus producciones como Lumpérica (1983), Por la patria (1986), El cuarto mundo (1988), El Padre Mío (1989), Vaca sagrada (1992) y Los vigilantes (1995).

En este artículo analizamos el texto El Padre Mío (1989) y estudiamos las categorías culturales y metafóricas en el apartado de la dedicatoria y la "Presentación" de la novela; luego, analizamos el texto propiamente dicho recurriendo a las categorías de interacciones comunicativas de Thompson (1998) y determinamos la memoria narrativa o "memorable" siguiendo la propuesta de Jelin (2002).

\section{UNA REVISIÓN DE LA RECEPCIÓN CRÍTICA DE SU OBRA}

La narrativa de Diamela Eltit recupera el testimonio y la memoria del cuerpo. Delinea la polisignificación del tema golpe entendido como sujeto, cicatriz, hematoma, fractura y mutilación. Para la escritora chilena (Eltit, 2009), su narrativa asume el tema de los cuerpos en crisis como una metáfora consecuente de la dictadura de Pinochet en sus dos modalidades: (1) el cuerpo como nación y (2) el cuerpo como ideología de sus sobrevivientes. Sin duda, ella es capaz de denunciar con la escritura el despojo, la distorsión y los efectos del acontecimiento militar.

El lenguaje que utiliza, en realidad, no es el lenguaje convencional o estructurado por el patrón lingüístico; ella modela el lenguaje literario de manera singular dentro de su creación. Es decir, sus creaciones gozan de ser complejas, con imágenes que atestiguan la ineficacia del Estado (Moraña, 2004). Sus textos son incomprensibles, insoportables e ininteligibles. De eso se trata, sugiere Sarlo (1987), pues dentro de la dictadura debía comunicarse con sus lectores, denunciar sus efectos y excesos. Por eso, Eltit emplea un lenguaje encriptado y encapsulado. Un lenguaje que evita los olvidos, los borrones de la 
memoria y que expone la fractura de los sobrevivientes y la desaparición de los ciudadanos (Lorenzano, 1999).

Para Richard (como se citó en Moraña, 2004), Eltit en realidad representa la "narrativa de la crisis" de Chile y, para ello, evita en su estructura textual el uso de los signos convencionales y propone una representación de lo escatológico, con sujetos expulsados de sus derechos y de su ciudadanía que narran desde los márgenes. En ese sentido, según Lorenzano (1999), Eltit apuesta en su narrativa por los narradores protagonistas que enuncian desde los intersticios: permite hablar a los sujetos negados y estigmatizados por el Estado-nación. Su escritura es la de los sobrevivientes como, por ejemplo, el representado en la novela El Padre Mío al exponer el entorno mental de su narradorpersonaje (un esquizofrénico) que nos permite escuchar-leer un discurso desarticulado, obsesivo, fragmentado e incoherente; que en palabras de Morales (2008) es uno de los textos ineludibles de la narrativa testimonial de Latinoamérica.

Por su parte, Eltit (2009) confesaba abiertamente que se debía escribir sobre los signos depresivos provocados por el poder militar de Pinochet. Esta identidad con nuevos signos de poder castrense, que reprimía a la ciudadanía y lo hacía por medio de la retórica retorcida, en tono impositivo, con palabras literales y oclusivas. Violencia de la dictadura supeditada a la filiación irrestricta del liberalismo como dogmas esencialistas y triunfalistas desenvueltos en Chile. En todo caso, Eltit escribe sobre elementos y marcas de una cultura impuesta que la lleva hacia su desaparición o, simplemente, a la locura.

Finalmente, Prado Traverso (1995) explica que los textos literarios de Eltit representan temas como la dictadura, la sexualidad, el autoritarismo, el feminismo, lo marginal y las diversas metáforas sobre los grupos étnicos en función de su cuerpo, su distribución ideológica, su voz y su testimonio. Por ello, se la ha considerado como una escritora que organiza sus escritos en textos bricolage con "testimonios disidentes" escritos desde y sobre la marginalidad:

La obra de Diamela Eltit se inserta en las llamadas poéticas de la crisis. La quiebra de códigos lingüísticos y arquitecturas narrativas convencionales, el carácter fragmentario, la acogida de distintas hablas, la presencia de una oralidad que permea el discurso escrito alterando su sintaxis constitutiva, la heteroglosia buscada como elemento desestabilizador de la estética y el orden social dominantes son algunos rasgos característicos de estas poéticas señalados por la crítica. (pp. 139-140)

Como vemos, los críticos coinciden en que la propuesta literaria de Eltit aborda el tema del cuerpo de/sobre la ciudad y el ciudadano, y el testimonio ficcional que recoge recuerdos desde sus espacios marginales; suele representar el lenguaje encriptado, circular, fragmentado y confuso sobre la situación y la consecuencia de la dictadura militar en Chile. 


\section{CATEGORÍAS METAFÓRICAS}

Cornejo Polar (1998) asume que las categorías provenientes de otros ámbitos son un riesgo, pues el empleo de préstamos semánticos trae consigo dificultades que pueden desplazar significaciones e incluso presentarse en un planteamiento hermenéutico que no rinda teóricamente.

No obstante, está de acuerdo en que los campos culturales y literarios pueden relacionarse. Para esto, sugiere que a partir de la epistemología crítica o categorías antropológicas (experiencias) puedan configurarse con los discursos étnicos ${ }^{1}$ (esfera de producción estética) que da como resultado la capacidad hermenéutica: el rendimiento teórico (el uso de las metáforas o metonimias).

El Padre Mío (1989), de Diamela Eltit, se estructura en tres partes: "Su primera habla (grabada en 1983)", "Su segunda habla (grabada en 1984)" y "Su tercera habla (grabada en 1985)". En la carátula presenta el paratexto con dos nombres: uno en la parte superior (Diamela Eltit) y otro en la parte inferior (Francisco Zegers). Dedica el texto a la artista visual Lotty Rosenfeld:

Este trabajo recoge grabaciones hechas al Padre Mío en 1983, 1984 y 1985. Las fotografías corresponden a videos tomados por Lotty Rosenfeld. La publicación de este libro ha sido posible por el editor y amigo, Francisco Zegers, quien ha compartido la opción por espacios y voces alternativas y, particularmente, por esta habla encontrada en la ciudad. Agradezco al escritor Gonzalo Muñoz su interlocución en torno a las ideas contenidas en la presentación. Agradezco, finalmente, a mi hija Dánisa por su inapreciable ayuda en la tarea de transcripción de cintas. (Eltit, 1989, p. 9)

Esta cita nos advierte que EPM se debe a un compromiso y participación de un grupo. En ese sentido, en la producción previa a la estructura del texto narrativo se debe considerar los siguientes aspectos: (a) la información se recoge de las grabaciones de cintas (audiovisual) y de las tomas de fotografías; (b) se incluye la participación del editor en la publicación; (c) se busca la intervención y el diálogo reflexivo con el poeta Gonzalo Muñoz $z^{3}$ y, finalmente, (d) se realiza la transcripción escritural de las cintas. Este proceso, según Eltit, debe ser comprendido como "montaje narrativo".

En el apartado titulado "Presentación", Eltit expone un sinfín de categorías metafóricas para comprender la organicidad de su texto. Una de ellas es la metáfora del

1 Cornejo Polar (1998) enfatiza que dichos discursos étnicos (literaturas étnicas) forman conciencia y se encuentran en ciertas dimensiones de la conciencia de los pueblos americanos, lo cual muestra manifestaciones discursivas complejas, es decir, la episteme de nuestro universo discursivo.

2 Empleamos el texto publicado por Francisco Zegers Editor en 1989. En adelante, EPM.

3 Es un poeta que trata sobre el cuerpo y la historia, y usa el lenguaje barroco y neobarroco. Además, usualmente, escribe ensayos sobre artes visuales (Becerra, 2014). 
"montaje narrativo", que proviene del discurso audiovisual e implica la reunión de trozos de película (fotografía y video); en este caso, el uso de dicho discurso hacia la composición escritural de un texto narrativo. También se encuentra el "programa nómada" referido al narrador-personaje, a este sujeto anónimo que se presenta con una silueta desposeída, habla desde su monólogo y emplea el lenguaje barroco como una "lengua móvil haciéndola estallar" (Eltit, 1989, p. 15). Asimismo, se tiene la metáfora "cuerpo del delirio" que representa el cuerpo del vagabundo, que se encuentra en tensión dramática, en condición errante, se desplaza en las calles, plazas y rincones de la ciudad, y encarna "físicamente la liberación apasionada del mundo de trabajo" (Eltit, 1989, pp. 13-14); y que, además, busca exteriorizar y exhibir un cuerpo lleno de "costra de una asentada sociedad" (Eltit, 1989, p. 12). También transporta "los objetos testimoniadores del pasado" como materiales acumulativos o evidencias testimoniales (ropas colgadas, diarios antiguos, piedras para una fogata, tarro lleno de agua). De la misma manera, se usa "el lenguaje angustiado" o el uso del lenguaje sin sentido, el circular o lenguaje barroco. Y, finalmente, la metáfora denominada es-cultura que se debe comprender en función del cuerpo que deambula y se disemina en los bordes, como un "ornamento" de una fachada arquitectónica en cataclismo, un cuerpo mirado y admirado que provoca una lectura recargada, pues presenta el "barroco visual pesadamente latino por el orden de su pobreza" (Eltit, 1989, p. 13). De esa forma:

La gama de verbalizaciones posibles se había instalado en la energía que sus cuerpos acusaban, augurando el desastre de la palabra posible de nombrar y de nombrarse. Sus cuerpos artísticos parecían encadenados a un eterno presente, a la instantaneidad de la mirada, y el olvido evidente de los ojos dispuestos a devorarlo todo, a disolverlo todo. (pp. 14-15)

Las categorías metafóricas propuestas por la escritora Diamela Eltit plantean un proyecto literario denominado estética de las significaciones culturales que, según su reflexión, representa la reunión del cuerpo, el uso del lenguaje barroco, la intertextualidad entre el texto audiovisual, el discurso cultural, el discurso performativo, la literatura y las lecturas de las diversas disciplinas humanísticas (sociología, antropología audiovisual, psicología e historia).

\section{INTERACCIÓN COMUNICATIVA Y LA FOTOGRAFÍA}

Continuamos con el análisis del apartado titulado "Presentación", “Su primera habla (grabada en 1983)", "Su segunda habla (grabada en 1984)" y "Su tercera habla (grabada en 1985)" de EPM. Para ello, seguimos a Thompson (1998), quien propone la existencia de tres tipos de interacción en la comunicación: (1) cara a cara, (2) mediática y (3) casi interacción mediática. 
En EPM se representa la interacción de las tres maneras. La primera corresponde a la interacción mediática que recurre al uso de video, fotografías y casetes ("en la tarea de transcripción de cintas"). Esta interacción implica la utilización de soportes técnicos u objetuales que permitan registrar los contextos diacrónicos (1983, 1984 y 1985); luego estos son incluidos en el proceso de la elaboración del texto literario como "montaje narrativo".

Según Barthes (1986), la fotografía presenta una lectura de códigos de tipo connotativo, la lectura que llega a ser histórica, que depende del "saber" del lector, ya que "es inteligible para el que aprehende sus signos" (p. 24), puesto que se lee desde su situación cultural. Los mecanismos de dicha lectura se verbalizan en el instante de su percepción, es de inmediato y "es cosa sabida que toda lengua toma partido acerca de las cosas, connota lo real, aunque solo sea en la medida en que lo recorta; las connotaciones de la fotografía, por tanto, coincidirían grosso modo con los grandes planos de connotación del lenguaje" (pp. 24-25). Eltit recurre a la lectura de las ciudades a partir del material fotográfico; comprende que la ciudad de Chile representada se encuentra en lo escatológico y que sus habitantes, los sobrevivientes, cruzaron la frontera de la cordura a consecuencia de la dictadura militar.

Así, en la "Presentación", explica que se filmaba, se tomaba fotografías a la ciudad, a los vecindarios, a los prostíbulos y a los "vagabundos". Luego, las investigadoras (Eltit y Rosenfeld) realizaban una interacción cara a cara con el sujeto expulsado, "el vagabundo", llamado Padre Mío, y grababan su testimonio de secuencias fragmentadas. La recolección del testimonio se llevó a cabo en la zona periférica y marginal ubicada en la comuna de Conchalí, a inicios de los ochenta:

Conocí a Padre Mío en 1983. La artista visual Lotty Rosenfeld me acompañaba en una inestable investigación en torno a la ciudad y los márgenes, investigación iniciada en 1980 y en la que ya habíamos pasado por múltiples hospederías, barrios prostibularios y diversas situaciones de vagabundaje que Lotty Rosenfeld iba documentando en video. (Eltit, 1989, p. 11)

La ciudad de Conchalí es el lugar en el que se cobija la sobrevivencia de los marginales y alberga a Padre Mío. La novela está saturada de los más usuales estereotipos marginales de la ciudad y de sus habitantes. Según Pollarolo (2015), el escritor latinoamericano apuesta por el mito civilizatorio de la integración y consolidación del espacio urbano y muestra el deterioro de las grandes capitales. De ahí que los escritores del siglo $x x$ hereden de los letrados coloniales la necesidad de nombrar y representar lo americano: construyen, inventan, recrean ciudades, "espacios estéticos", a partir de lo visible y exponen sus experiencias o vivencias personales para la construcción de la identidad y la creación artística: "Esta necesidad de representar, crear, inventar las ciudades hispanoamericanas que arranca, ya se ha visto, en la literatura colonial y prosigue en el XIX 
y el $x x$, ha sido determinante en la invención y construcción de identidades" (Pollarolo, 2015, p. 136).

En el caso de EPM, se representa la ciudad como "el espacio literario" o la "espacialidad literaria" periférica. Según la reflexión de Eltit (1989), el cuerpo sobreviviente o testigo es, en realidad, Chile:

Es Chile, pensé. Chile entero y a pedazos en la enfermedad de este hombre; jirones de diarios, fragmentos de exterminio, sílabas de muerte, pausas de mentira, frases comerciales, nombres de difuntos. Es una honda crisis del lenguaje, una infección en la memoria, una desarticulación de todas las ideologías. Es una pena, pensé. (p. 17)

Eltit (1989) explica que el trabajo de investigación, realizado inicialmente por la escritora y la artista visual, buscaba recoger evidencias sobre las consecuencias de la dictadura de Pinochet. Y lo que hallaron en las ciudades marginadas (barrios, hospedajes, prostíbulos) fue la presencia de "figuras del vagabundaje urbano", desplazándose como desechos que cargan "objetos testimoniadores de la existencia de un pasado" (p. 12). Eltit (1989) confiesa que de toda la investigación se logró ubicar el testimonio oral y también corporal de un peculiar sobreviviente. La voz desencajada, con los recuerdos confusos y el lenguaje barroco, solo les evidenciaba la confusión, angustia y desosiego de Padre Mío: "Desde dónde recoger esta habla era la pregunta que principalmente me problematizaba, especialmente, porque su decir toca múltiples límites abordables desde disciplinas formalizadas y ajenas para mí, como la psiquiatría, por ejemplo" (p. 16).

No olvidemos, entonces, que el texto narrativo es un "montaje narrativo" que implica el acto de llevar la imagen o el texto audiovisual hacia la escritura, técnica conocida como écfrasis ${ }^{4}$ literaria, empleada por diversos escritores:

Buscaba, especialmente, captar y capturar una estética generadora de significaciones culturales, entendiendo el movimiento vital de esas zonas como una suerte de negativo - como el negativo fotográfico-, necesario para configurar un positivo -el resto de la ciudad-, a través de una fuerte exclusión territorial para así mantener intacto el sistema social tramado bajo fuertes y sostenidas jerarquizaciones. (Eltit, 1989, p. 11)

Eltit, a partir del texto audiovisual, produce una historia que refiere la ciudad escatológica en la que habita Padre Mío. Traza el imaginario cultural que define la identidad chilena durante la dictadura. Aquí se va plasmando la tercera interacción relacionada, casi interacción mediática, que involucra lo social y los medios de comunicación de masas

4 La écfrasis es una técnica descriptiva que se asume como pintar con las palabras escenas de narración; presenta viveza descriptiva, sus personajes no escapan del punto de vista pictórico, se detalla y describe las imágenes en la escritura para que así lo entienda el lector. 
(libros, revistas, periódicos, radio, televisión y cine), de manera particular, la producción de una obra literaria titulada El Padre Mío. Según Eltit (1989): “Actuar desde la narrativa. Desde la literatura [...] instala el efecto conmovedor de esta habla" (p. 16). Es significativo e ineludible hablar desde la literatura sobre un Chile agonizante. Así pues, dentro del texto en que ubicamos al narrador-personaje, el sobreviviente es quien habla desde la "locura", que según Lacan es el sujeto que logró tocar lo real y conoce "lo grotesco, lo horrible" de la realidad. Por eso, Eltit (1989) señala: "Debo enfatizar su extraordinaria capacidad de sobrevivencia, dado que su mente estaba detenida en un punto único" (p. 15); es un sujeto del delirio, el supuesto desprendido de todo lo social, lo cultural y lo ideológico.

\section{MEMORIA NARRATIVA}

En este apartado, comprendemos la definición de la memoria y cómo se representa en EPM. La memoria es la producción de recuerdos a través de diferentes mecanismos, ya sea de manera voluntaria o involuntaria, que teje interpretaciones en las que estallan las imágenes del tiempo-ahora. Asimismo, la memoria funciona como un operador que otorga sentido al pasado; incluso puede construir los sentidos de este y armar su narrativa en la cual los sujetos buscamos lo que ya no somos (Jelin, 2003, 2004).

Hay dos tipos de memoria: la habitual y la narrativa o "memorable". Esta última se expresa en forma narrativa, convirtiéndose en la manera por la cual el sujeto puede encontrar o construir los sentidos del pasado, con la memoria que aún puede relatar hechos con "un mínimo de coherencia" (Jelin, 2003, p. 32). El acto de rememorar implica: (1) tener una experiencia pasada que se activa en el presente, ya sea por un deseo o un sufrimiento, unidos a veces a la intención de comunicarla; (2) pueden ser acontecimientos importantes en sí mismos, como también aquellos que cobran una carga afectiva y un sentido especial en el proceso de recordar o rememorar. La memoria "memorable" asume dos notas centrales: el pasado cobra sentido en su enlace con el presente, en el acto de rememorar/olvidar; y esta interrogación sobre el pasado es un proceso subjetivo, es siempre activo y construido socialmente en diálogo e interacción.

Las características para llevar a cabo la memoria "memorable" son las siguientes: (a) la importancia de tener y no tener palabras para expresar lo vivido; (b) construir la experiencia y la subjetividad a partir de eventos y acontecimientos que nos "chocan"; y (c) es necesario que el sujeto, para transformar la memoria en experiencia, deba encontrar las palabras y ubicarse dentro de un marco cultural que haga posible la comunicación y la transmisión, puesto que las memorias son simultáneamente individuales y colectivas, ya que "en cualquier momento y lugar, es imposible encontrar una memoria, una visión y una interpretación única del pasado, compartidas por toda una sociedad" (Jelin, 2002, p. 30). Sin embargo, la primera y segunda características apelan, a su vez, al acto de 
asumir la importancia de las experiencias traumáticas que produce la masividad del impacto, que crea así un vacío en la capacidad de "ser hablado" o "contado"; se provoca un agujero en la capacidad de representación psíquica, faltan las palabras, faltan los recuerdos, la memoria queda desarticulada y solo aparecen huellas dolorosas, patológicas y silentes; lo traumático altera la temporalidad de otros procesos psíquicos y la memoria no los puede tomar; dice el narrador: "Pero a mí me planearon por asesinato y enfermo mental y se pagó un dinero importante por mi persona, pero no en complicidad" (Eltit, 1989, p. 56).

En EPM, el narrador-personaje es un vagabundo y es un "esquizofrénico" que desde su individualidad conecta lo colectivo, que cuenta una experiencia: sobrevivió; y su cuerpo quedó hecho piltrafa; mientras que su mente se halla fragmentada y desarticulada, lo que evidencia el agujero psíquico por medio de su testimonio incoherente y confuso:

El mismo señor Pinochet es el señor Colvin, es el mismo jugador William Marín de Audax italiano, el mismo. Él es el señor Colvin, el señor Luengo, el rey Jorge, uno de ellos, el retirado, ya que ustedes lo vieron con bote en el Hospital Siquiátrico. (Eltit, 1989, p. 29)

En EPM también la memoria se halla fracturada, ya que desde esa voz del "vagabundo-Padre Mío" insiste en el uso del lenguaje incoherente, circular, que crea confusión y desasosiego al lector:

Yo voy a hablarle muy franco: yo le di parte del sufragio al señor Allende por el Partido Socialista y Comunista. Y hay algo más: cuando estuve en los otros Estados, el Partido Comunista, finalmente, no existe, ahora se llama Organización de Seguridad Comunista del Estado, pero no Partido Político. (p. 41)

La memoria, la conmemoración, el recuerdo y el olvido son procesos dinámicos que responden a una compleja trama social, cultural y política; "son procesos de significación y resignificación subjetivos donde los sujetos de la acción se mueven y orientan (o se desorientan y se pierden) entre 'futuros pasados', 'futuros perdidos', 'pasados que no pasan'" (Jelin, 2004, p. 103). La memoria en EPM se presenta como un proceso subjetivo individual (monólogos) o perteneciente al colectivo cultural (conversaciones), anclado en experiencias y en "marcas" de tipo material y simbólico, de acuerdo con el contexto político y cultural. En "Su segunda habla (grabada en 1984)", el narrador dice:

Ignoraba lo que estaba relacionado con el Padre Mío, porque fui planeado en ese tiempo para ser asesinado y volví a ser planeado por lo que le estoy conversando a usted yo. Pero debería servir de testimonio yo. Hospitalario no puedo servir, porque ahí tienen empleada la táctica de la complicidad. (Eltit, 1989, pp. 56-57)

Existen diversas formas de expresar las memorias singulares fijadas en nuestras experiencias o huellas (materiales o simbólicas) que se manifiestan a través de diversos 
soportes de la memoria. En EPM, en el primer capítulo "Su primera habla (grabada en 1983)", el narrador-personaje narra sin interrupciones, aunque "conversa" y se nota las huellas o recuerdos traumáticos sobre la dictadura:

El Padre Mío les da las órdenes a todos ustedes, ilegal. Yo esto lo vine a saber a la edad de treinta y un años, yo porque cuando vivió conmigo nunca me explicó que ocupó cargos en la Administración. (Eltit, 1989, p. 25)

El soporte de la memoria utiliza mecanismos de la memoria colectiva. Este soporte transmite y usa diversos medios ya procedentes de las tradiciones orales o registros como los escritos, imágenes, cantos, símbolos, lugares, representaciones teatrales, espacios y acciones capaces de transmitir recuerdos, habilidades, rituales y rememoraciones. Emplea espacios que ayudan a ubicar las imágenes, marcas o escenarios que concedan el valor de las evocaciones (Regalado, 2007). Efectivamente, Eltit (1989) apuesta por representar los diversos registros en EPM. En "Su segunda habla (grabada en 1984)", aduce Padre Mío:

Yo no soy cómplice de ellos, con el exterminio general. Por eso, no se confíen ustedes, ustedes están planeados, y a mí me planearon porque a ellos no les convenía yo, y porque el Padre Mío subsiste de ingresos ilegales bancarios de concesiones y de solicitud al personal de la Administración. (pp. 47-48)

La memoria se presenta de diversas maneras con cinco soportes: (1) el de la escritura (libros de historia, memorias, agendas, diarios, periódicos), los monumentos, las exposiciones y la fotografía; (2) los medios simbólicos ${ }^{5}$, como los dibujos, la música, la poesía, los grafitis, los murales, la escultura y la pintura; (3) el medio audiovisual: mapa interactivo, películas, planos de sitio, mapas urbanos, maquetas electrónicas, animaciones, documentales y videos (Pouligny, 2004); (4) performativos. como la danza, las actuaciones teatrales y las expresiones musicales (Jelin, 2002); y, finalmente, (5) la sensibilidad sensorial o corporal como, por ejemplo, un lunar, una cicatriz, la agitación al recordar o mirar algún objeto, etcétera.

EPM, a partir del soporte audiovisual y escritural, nos propone un texto ficcional que convoca y reconstruye los recuerdos mezclados con sus testimonios fragmentados, circulares y confusos. Según Halbwachs (2004), a medida que el sujeto rememora, retrocede en el tiempo, cambia el recuerdo, porque "algunos rasgos se difuminan y otros vuelven a saber, según la perspectiva desde la que lo miremos, es decir, según las nuevas condiciones en que nos encontremos cuando nos fijemos en él" (p. 74). En el capítulo titulado "Su tercera habla (grabada en 1985)", dice Padre Mío: “El Padre Mío

5 Para Pouligny (2004), los "símbolos nos sirven de mediadores permanentes con el mundo que nos rodea y con nosotros mismos. La simbolización es la base de la cultura humana, desde las interacciones precoces entre el niño y sus padres hasta los complejos procesos de transmisión de la memoria colectiva, sentimiento de pertenencia a una historia familiar y social" (p. 281). 
siempre usurpó las garantías bancarias anteriores, aunque hubiera ocupado el cargo de presidente de la República. Pero el Padre Mío siempre dio las órdenes aquí en el país" (Eltit, 1989, p. 62).

Asimismo, en la novela la memoria se relaciona con el marco de tiempo, se conserva como una huella, una fecha sobre los eventos políticos y sociales, examina detalles del contexto de la dictadura chilena, sobre todo, los inicios de los años ochenta. Enmarca el tiempo colectivo y social, que incluye a todas las duraciones individuales y las asocia con el marco espacial de 1983, 1984 y 1985. Así, "el tiempo, concebido como algo que se extiende a todos los seres, no es más que una creación artificial obtenida mediante la suma, combinación y multiplicación de datos tomados de las duraciones individuales y solo de ellos" (Halbwachs, 2004, p. 94). El recuerdo dislocado de Padre Mío refiere lo siguiente:

A mí me intentaron matar antes por él, cuando necesitó dinero él, ya que lo necesitó cuando mataron a mis familiares. Se deshizo de ellos porque a él no le convenía, ya que ellos fueron elegidos para despistar, porque él subsiste de ingresos bancarios ilegales, pero él es el que da las órdenes aquí en el país. (Eltit, 1989, p. 26)

Por tanto, el tiempo universal son todos los hechos de los grupos e individuos en un tiempo homogéneo, tiempo histórico que abarca la vida de los pueblos, del pasado histórico; de acuerdo con un cuadro sincrónico que se aproxima a todos los acontecimientos, se refiere a los primeros años de los ochenta en Chile. Dice el narrador-personaje: "Si ustedes no se ponen de acuerdo, la mayoría, están todos planeados para el exterminio. Pero yo no soy cómplice en esos asuntos" (Eltit, 1989, p. 28).

Finalmente, lo analizado nos permite comprender con Lienhard (2000) que EPM propone el testimonio y la memoria recreada desde la ficción. Es decir, el testimonio de Padre Mío contado desde la "ficción" o la escritura "documental" audiovisual revisada por Eltit, que presenta el recurso de la "dialogicidad". Así, como agente-escritor, escritor-antropólogo y escritor-artista plástico, recrea y representa un escenario con su propia verdad que permite el diálogo entre las voces y los discursos a partir de un personaje-narrador que intercala recuerdos sobre la dictadura militar en Chile, consciente del sentido crítico y de la competencia del lector, quien busca "un testimonio muy real de la relación entre un intelectual y sus 'informantes' populares" (Lienhard, 2000, p. 793) en una obra dialógica como lo es EPM.

6 Implica la propuesta del soviético Mijaíl Bajtín, quien propone el diálogo de las voces, los lenguajes, los discursos y las ideologías. 


\section{CONCLUSIÓN}

La novela El Padre Mío, de Diamela Eltit, ha sido estudiada por diversos críticos literarios, quienes aducen que su propuesta narrativa es de la disidencia o narrativa testimonial. En la dedicatoria y la "Presentación" se proponen categorías metafóricas como "montaje narrativo", "programa nómada”, “cuerpo del delirio", "el lenguaje angustiado", "objetos testimoniadores del pasado", "es-cultura", organizadas como un proyecto literario denominado estética de las significaciones culturales. Además, en el análisis textual se efectúan los tres tipos de interacción comunicativa: cara a cara, mediática y casi interacción mediática. Asimismo, la memoria ficcional representada en "Su primera habla (grabada en 1983)", "Su segunda habla (grabada en 1984)" y "Su tercera habla (grabada en 1985)" representa la memoria narrativa o memorable como un proceso subjetivo individual (monólogo) perteneciente al colectivo cultural chileno; el narrador-personaje narra sus testimonios desde la locura sobre los hechos traumáticos (antes, durante y después), desde una ciudad periférica, la comuna de Conchalí, acerca de la dictadura militar chilena en los ochenta. De ese modo, la estrategia escritural en EPM es transgresiva y plurisignificativa en temas culturales narrados desde la literatura latinoamericana.

\section{REFERENCIAS}

Barthes, R. (1986). Lo obvio y lo obtuso. Imágenes, gestos y voces. Paidós.

Becerra, F. (2014). La historia deseada: a partir de una operación neobarroca en Gonzalo Muñoz. Revista Laboratorio, 11. https://revistalaboratorio.udp.cl/index.php/ laboratorio/article/view/192/185

Cornejo Polar, A. (1998). Mestizaje e hibridez: los riesgos de las metáforas. Apuntes. Revista de Crítica Literaria Latinoamericana, 47, 7-11.

Eltit, D. (2009). Las dos caras de La Moneda. En N. Richard (Ed.), Debates críticos en América Latina 3. 36 números de la Revista de Crítica Cultural (1990-2008) (pp. 49-55). Arcis; Cuarto Propio.

Eltit, D. (1989). El Padre Mío. Francisco Zegers Editor.

Garza, E. (2008). Écfrasis: el "Pintar con palabras" de Bécquer. En S. Juan-Navarro y J. Torres-Pou (Eds.), Memoria histórica, género e interdisciplinariedad. Los estudios culturales hispánicos en el siglo XxI (pp. 227-236). Biblioteca Nueva.

Halbwachs, M. (2004). La memoria colectiva. Prensas Universitarias de Zaragoza.

Jelin, E. (2002). Los trabajos de la memoria. Siglo Veintiuno Editores.

Jelin, E. (2003). Memorias y luchas políticas. En C. I. Degregori (Ed.), Jamás tan cerca arremetió lo lejos. Memoria y violencia política en el Perú (pp. 27-48). Instituto de Estudios Peruanos. 
Jelin, E. (2004). Los derechos humanos y la memoria de la violencia política y la represión: la construcción de un campo nuevo en las ciencias sociales. Estudios Sociales, 27, 91-113.

Lienhard, M. (2000). Voces marginadas y poder discursivo en América Latina. Revista Iberoamericana, 193, 785-798.

Lorenzano, S. (1999). Los cuerpos de la transgresión. En L. Gutiérrez de Velasco, G. Prado y A. Domenella (Comps.), De pesares y alegrías. Escritoras latinoamericanas y caribeñas contemporáneas (pp. 109-121). El Colegio de México; Universidad Autónoma Metropolitana.

Morales, L. (2008). La verdad del testimonio y la verdad del loco. Revista Chilena de Literatura, 72, 193-205.

Moraña, M. (2004). Diamela Eltit: el espejo roto. En Crítica impura. Estudios de literatura y cultura latinoamericana (pp. 289-291). Iberoamericana Vervuert.

Pollarolo, G. (2015). Un Machu Picchu, por favor: el Cuzco en una novela. En A. Baraibar y M. Vinatea (Ed.), Viajes y ciudades míticas. Colección BIADIG.

Pouligny, B. (2004). ¿Cómo facilitar la expresión de las memorias de la violencia? Perú, el país de las memorias heridas: entre el (auto)desprecio y la amargura. En R. Belay (Ed.), Memorias en conflicto. Aspectos de la violencia política contemporánea (pp. 275-284). Red para el Desarrollo de las Ciencias Sociales en el Perú.

Prado Traverso, M. (1995). La obra literaria de Diamela Eltit, testimonios desde la marginalidad. Nueva Revista del Pacífico, 40, 139-146.

Regalado, L. (2007). Clío y Mnemósine. Estudios sobre historia, memoria y pasado reciente. Universidad Nacional Mayor de San Marcos; Pontificia Universidad Católica del Perú, Fondo Editorial.

Reyes, M. (2005). Eltit y Spivak: dos visiones de la subalternidad. El Hablador, 9. https:// www.scribd.com/document/370541368/Eltit-y-Spivak-Dos-Visiones-de-LaSubalternidad

Sarlo, B. (1987). Política, ideología y figuración literaria. En D. Balderston (Ed.), Ficción y política. La narrativa argentina durante el proceso militar (pp. 30-59). Alianza Editorial.

Thompson, J. (1998). La media y la modernidad. Una teoría de los medios de comunicación. Paidós. 